Dr RADE PANTIĆ, asistent

Fakultet za medije i komunikacije

Univerzitet Singidunum

Beograd, Danijelova 32

rade.pantic@fmk.edu.rs

originalan naučni rad

primljeno: 24. februar 2016.

791:316.72(497.11)"1945/1965"

prihvaćeno: 28. septembar 2016.

\title{
ELITNO I POPULARNO U JUGOSLOVENSKOJ FILMSKOJ KULTURI 1945-1965.
}

APSTRAKT: Cilj rada je da pokuša da primeni teoriju kulture francuskog sociologa Pjera Burdijea, koja je zasnovana na distinkciji između elitnog i popularnog, na domen jugoslovenske filmske kulture u periodu 1945-1965. godine. Budući da je ova teorija pisana imajući u vidu francuski posleratni kapitalistički sistem, pokušaćemo da pokažemo izmenjene karakteristike koje pojmovi elitnog i popularnog zadobijaju u jugoslovenskom socijalističkom društvenom sistemu i njegovoj filmskoj kulturi.

KLJUČNE REČI: elitno, popularno, film, kultura, socijalizam, Burdije

„Bioskopi pokazuju odsustvo svake umetnosti. Oni stvaraju samo varljiva zadovoljstva niže vrste. Štetni su jer svojom raskalašnom sadržinom kvare naravstvenost; ubitačni su, zbog svog senzualizma, po živce; a zbog svoga žestokog dejstva na maštu, kobni su i po zdrav estetički sud kod sveta. Od njih preti opasnost naročito omladini, i ženskoj i muškoj. Zbog toga se treba protivu njih boriti." 1

Ovaj isečak iz članka srpskog pedagoškog lista Nastavnik iz 1913. karakterističan je pokazatelj negativne recepcije filma kao novog medija od strane domaće kulturne elite. Pejorativan stav intelektualaca prema filmu u jugoslovenskoj sredini zadržaće se do kraja Drugog svetskog rata. Dragan R. Aćimović je 1939. sa žaljenjem konstatovao negiranje statusa umetnosti filmu od strane jugoslovenskih intelektualaca: „Nijedan filmski list, nijedna

${ }^{1}$ Гргур Берић, „Биоскопске представе и ученици“, у: Беоіраgски филмски критии-

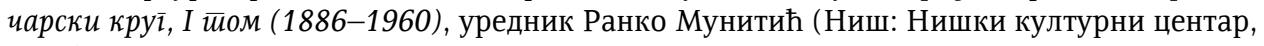
2002), 29. 
filmska rubrika u ozbiljnim književno-umetničkim revijama i časopisima, nijedna veća publikacija o filmskoj umetnosti! Sve to najbolje tumači kako u Jugoslaviji filmsku umetnost ili ne poznaju ili ne vole oni koji su najpozvaniji za to: umetnici, književnici, estetičari, kritičari." ${ }^{2}$ Dvadeset pet godina kasnije, u doba navodnog besklasnog društva socijalističkog samoupravljanja, eminentni jugoslovenski filmski teoretičar i profesor Dušan Stojanović će pisati da je filmska umetnost „aristokratski fenomen“. ${ }^{3}$

Ova promena recepcije filma od strane intelektualne elite predstavlja pokazatelj promene kulturnog statusa filma. U periodu pre rata film je bio kategorizovan kao popularna, masovna kultura i stoga nije smatran delom 'kulture' u smislu kanonizovane, respektabilne visoke nacionalne kulture. ${ }^{4}$ Budući da ne ulazi u domen 'kulture', film u ovom periodu nema institucionalizovan status umetnosti, već se smatra 'lakom zabavom' i stoga industrijskom delatnošću. Institucionalizacija filma kao umetnosti u Jugoslaviji desiće se tek po dolasku komunista na vlast u vidu estetsko-političkog koncepta socijalističkog realizma.

Prema francuskom sociologu Pjeru Burdijeu (Pierre Bourdieu) podela na elitnu i popularnu kulturu, to jest na umetnost i zabavu, zapravo krije socijalnu distinkciju između viših i nižih klasa. Koristeći se Burdijeovom kulturnom teorijom i njegovim konceptom kulturnog kapitala, ${ }^{5}$ pokušaćemo da pokažemo promenljive paradigme filma kao umetnosti u jugoslovenskom društvu tokom perioda 1945-1965. godine. Budući da je ova teorija pisana imajući u vidu kapitalistički društveni sistem, nastojaćemo da pokažemo izmenjene karakteristike koje pojmovi elitnog i popularnog zadobijaju u jugoslovenskom socijalističkom sistemu. Uzimajući kao polaznu tačku tvrdnju britanskog teoretičara kulture Džona Storija (John Storey) da su elitna i popularna kultura, to jest highbrow i lowbrow kultura, kategorije koje je izumela intelektualna elita, ${ }^{6}$ nećemo se baviti tekstualnom analizom filmova koji pripadaju ovim grupama već ćemo istraživati promenljive načine konstruisanja određenih grupa filmova kao kategorija umetničkog,

${ }^{2}$ Драган Р. Аћимовић, „Треба ли код нас писати о филму?“, у: Беоіраgски филм-

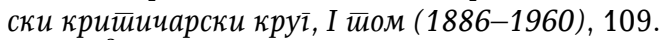

${ }_{3}^{3}$ Dušan Stojanović, Velika avantura filma (Beograd/Novi Sad: Prometej, 1998), 75.

${ }^{4}$ Filmska delatnost je izuzeta iz Ministarstva prosvete, pod čijom jurisdikcijom su se nalazile tradicionalne umetnosti, i prepuštena Ministarstvu trgovine i industrije, a bioskopi su kao i obične radnje opterećeni sa 40\% poreza. Videti: Љубодраг Димић, Кулишрна

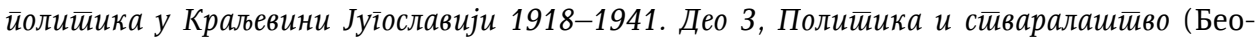
град: Стубови културе, 1997), 326.

${ }^{5}$ Za dobar uvod u kulturnu teoriju Pjera Burdijea videti: Bridget Fowler, Pierre Bourdieu and Cultural Theory. Critical Investigations (London: Sage, 1997).

6 John Storey, Inventing Popular Culture. From Folklore to Globalization (Oxford: Blackwell, 2003), xi. 
odnosno popularnog filma kroz intelektualne diskurse. Budući da intelektualna kritičarska analiza nekog dela „nije samo pomoć namenjena da dâ prednost razumevanju i uvažavanju, nego trenutak stvaranja dela, njegovog značenja i vrednosti“" ${ }^{7}$ pokušaćemo da prikažemo filmsku kulturu kao arenu u kojoj se vodi politička borba označavanja, koja je uvek zavisna od promenljivih relacija društvene moći.

\section{Elitno i popularno}

Prema Burdijeu podela na elitnu i popularnu kulturu odslikava društvenu podelu. Kultura služi razlikovanju između društvenih klasa i reprodukuje klasnu podelu, dok istovremeno prikriva društvenu prirodu takvih distinkcija pozivanjem na univerzalije estetike i ukusa. Funkcija obrazovnog kulturalnog aparata umetničkih kritičara i estetičara jeste da proizvede mit o nepristupačnosti i složenosti visoke umetnosti, kao i da putem obrazovnih i kulturnih državnih institucija odredi 'pravilne' načine recepcije umetničkih dela koja ulaze $\mathrm{u}$ kanon visoke kulture. Visoka umetnost je tako označena kao distancirana od svakodnevice: ona odvaja estetsko od svakodnevnog i vrednuje umetnost prema stupnju njenog obraćanja estetskim univerzalijama. Ova distanca je dvojna i podrazumeva distanciranje recipijenta od umetničkog dela kao i distanciranje dela od banalnosti svakodnevice. Ona zahteva kritičara koji će kontrolisati značenja i reakcije na umetničko delo i procese obrazovanja kojim se ljudi obučavaju kako da cene viso$\mathrm{ku}$ umetnost. Ustanovljenje estetske superiornosti visoke umetnosti $\mathrm{u}$ odnosu na dela popularne kulture tako ima ulogu da 'naturalizuje' superiorniji ukus obrazovanih viših klasa u odnosu na niže. „Ukus klasifikuje klasifikatora", ${ }^{8}$ kako piše Burdije. Poznavanje i konzumacija visoke umetnosti daje njenim poštovaocima određenu društvenu moć, koju Burdije naziva kulturni kapital, i ona je povezana sa društveno-ekonomskim statusom i omogućava njenom posedniku ulazak u elitne društvene krugove. Na taj način kulturni ukus učestvuje $u$ reprodukciji socijalne nejednakosti. Ekonomska nejednakost biva prevedena u kulturalnu ispunjavajući „društvenu funkciju legitimisanja društvene razlike." ${ }^{9}$ Kulturne distinkcije se na ovaj način pokazuju kao 'prirodna dispozicija', a zapravo su dobijene porodičnim vaspitanjem i edukativnim sistemom viših klasa. Tako se stvara iluzija da umetnička dela poseduju univerzalnu, bezvremenu vrednost, dok je ta

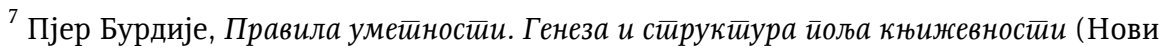
Сад: Светови, 2003), 247.

${ }^{8}$ Истй $0,6$.

${ }^{9}$ Pierre Bourdieu, Distinctions. A Social Critique of the Judgement of Taste (London: Routledge, 1984), 7. 
vrednost zapravo posledica borbe za društvenu moć $u$ jednom specifičnom istorijskom trenutku.

Popularna kultura je prema Burdijeu kultura klasno podređenih i ona se odlikuje odbacivanjem svake distance između estetike i svakodnevice i aktivnim učestvovanjem tokom recepcije. Ona je relevantna samo u odnosu na neposredan društveni kontekst recipijenta i koristi umetnička dela funkcionalistički kao i svaku drugu robu i isto tako je odbacujući ako je nepraktična. Popularna kultura se u intelektualnom diskursu zasniva kao 'drugo' od visoke kulture ${ }^{10}$ gde dobija pejorativan naziv masovna kultura. Svoju estetiku i način korišćenja visoka kultura zasniva u suprotnosti prema kulturi podređenih klasa. Iza navodno neutralne, prirodne i estetske hijerarhije kulturnih produkata kriju se zapravo klasni, konstruisani, političkoekonomski interesi.

Burdijeova analiza estetskih distinkcija uslovljenih društvenom borbom za moć zasnovana je na sociološkoj analizi francuskog društva i ograničena je unutardržavnim društvenim relacijama. Međutim, posmatranje socio-kulturalne podele jednog društva treba da uzme u obzir i internacionalne, međudržavne konstelacije moći. Nacionalno bazirane kulturalne hijerarhije isprepletene su uvek sa globalnim kretanjima i kultura ima neizbežnu internacionalnu dimenziju koju Burdije zanemaruje. ${ }^{11}$ Ova dimenzija je krucijalna za ovaj rad budući da je posleratna filmska kultura Jugoslavije situirana u okvir hladnoratovske konstelacije moći Evrope podeljene na dva bloka. Na isti način na koji je unutardržavna politika preko umetnosti kulturalizovana, za vreme Hladnog rata geopolitička borba za dominaciju između dva bloka zadobija dimenziju kulturnog rata. ${ }^{12}$ Kultura na ovom polju funkcioniše kao marker ideoloških distinkcija dva različita ideološka sistema koji se konstituišu u opoziciju jedan prema drugom.

\section{Film u socijalističkom realizmu}

Dolaskom na vlast Komunističke partije Jugoslavije (KPJ) menja se kulturni status filma. Komunisti su od Lenjina nasledili shvatanje filma kao 'najvažnije umetnosti', nove umetnosti koja najbolje odražava novo socijalističko društvo. Komitet za kinematografiju Vlade FNRJ osnovan je 1946. i stavljen pod nadzor Ministarstva za prosvetu i kulturu, ${ }^{13}$ čime je film, za

${ }^{10}$ John Storey, „Popular Culture as the 'Other' of High Culture“, u: Inventing Popular Culture, 32-47.

${ }^{11}$ Janet Harbord, Film cultures (Sage: London, 2002), 97.

12 David Caute, The Dancer Defects. The Struggle for Cultural Supremacy during Cold war (Oxford: Oxford University Press), 2003.

${ }^{13}$ Петар Волк, Срйски филм (Београд: Институт за филм, 1996), 319-322. 
razliku od predratnog perioda, kategorizovan kao deo visoke nacionalne kulture. Institucionalizacija filma kao umetničke kategorije obavljena je u kontekstu kulturnog koncepta socijalističkog realizma. Sredinom tridesetih KPJ prihvata socijalistički realizam kao zvaničnu platformu partije u oblasti kulturne politike pod uticajem direktiva koje dolaze iz SSSR-a. Dolaskom KPJ na vlast posle rata socijalistički realizam postaje zvaničan kulturni model jugoslovenske države. Na političkom planu FNRJ pokazuje svoju privrženost SSSR-u međudržavnim ugovorom aprila 1945. i odbijanjem Maršalove pomoći jula 1947, čime se jasno pozicionira uz Istočni blok zemalja „narodne demokratije“ $u$ Hladnom ratu. ${ }^{14}$ Prihvatanjem socijalističkog realizma kao zvanične državne doktrine na polju kulture izražava se političko opredeljenje nove vlasti. Tako je socijalistički realizam na unutrašnjem planu trebalo da ukaže na prekid sa građanskom, buržoaskom kulturnom ideologijom, a na spoljnopolitičkom jasnu opoziciju zapadno-kapitalističkim državama i svrstavanje uz Istočni blok u Hladnom ratu.

Prema nemačko-ruskom istoričaru umetnosti Borisu Grojsu (Boris Groys) karakteristika socijalističkog realizma jeste brisanje razlike između elitne i popularne kulture. Socijalistički realizam, po njegovom mišljenju, nije u suprotnosti sa modernističkom umetnošću ruske i sovjetske avangarde, kako je uvreženo mišljenje, već upravo predstavlja realizaciju utopijskog avangardnog projekta spajanja umetnosti sa svakodnevicom. ${ }^{15}$ Dok se kultura kapitalističkih sistema odlikuje rascepom na visoku i nisku, to jest na elitnu i popularnu kulturu, označavajući na taj način prema Burdijeu društvo zasnovano na klasnoj distinkciji, kultura socijalističkoj realizma briše ovu granicu označavajući projekat besklasnog društva. U brisanju granice između visoke i niske kulture Grojs vidi ostvarenje avangardnog sna totalne fuzije umetnosti i života koju socijalistički realizam ostvaruje. ${ }^{16}$ Svakodnevni život tako biva uređen prema principu totalnog umetničkog dela (Gesamtkunstwerk) sovjetske države, iza koga stoji Staljin kao ultimativni avangardni umetnik. Poništavanjem ideje autonomnog umetničkog polja na kome se zasniva kapitalistička elitna kultura, socijalistički realizam umetnika svodi na nivo običnog radnika čiji je zadatak ispunjavanje političkog projekta partijske avangarde. Odatle socijalistički realizam ne predstavlja popularnu kulturu, iako je predviđen za celokupnu populaciju, već elit-

${ }^{14}$ Branko Petranović, Istorija Jugoslavije 1918-1988, III knjiga: Socijalistička Jugoslavija 1945-1988 (Beograd: Nolit, 1988), 181.

${ }^{15}$ Boris Groys, „The Birth of Socialist Realism from the Spirit of the Russian AvantGarde", in: Post-Impressionism to World War II, ed. Debbie Lewer (Oxford: Blackwell, 2006), 274-295.

${ }^{16}$ Boris Groys, „The Struggle against Museum; or, The Display of Art in Totalitarian Space“, in: Museum Culture. Histories, Discourses, Spectacles, ed. Daniel J. Sherman, Irit Rogoff (London: Routledge, 1994), 156. 
nu kulturu masovno distribuiranu. Za razliku od zapadne tržišne popularne umetnosti koja uzima u obzir ukus recipijenata i trudi se da ga zadovolji, socijalistički realizam ima za cilj direktnu edukaciju, inspirisanje i vođenje masa. Slogan da „umetnost mora biti realistična $u$ formi, a socijalistička $u$ sadržaju" značio je da umetnost mora biti pristupačna masama na nivou forme, iako su njen sadržaj i ciljevi ideološki determinisani i usmereni ka reedukaciji stanovništva prema potrebama novog društva i njegovih sistema vladanja. ${ }^{17} \mathrm{U}$ suprotnosti sa kapitalističkim društvom gde postoji distinkcija između dve različite kulture namenjene dvema klasama, u socijalističkom sistemu postoji jedna kultura, a klasna distinkcija se javlja između vladajuće birokratske strukture i ostatka stanovništva kome partijski aparat nameće uniformnu kulturu. Milovan Đilas je u svom disidentskom periodu tvrdio da komunistička revolucija nije donela besklasno društvo, već nove društveno-ekonomske odnose dominacije u kojoj partijska birokratija predstavlja novu dominantnu klasu koja je uzela na sebe da „upravlja i raspolaže formalno podržavljenom, podruštvljenom imovinom, kao i čitavim životom uopšte." 18

Ovaj navodni dvostruki karakter kulture socijalističkog realizma, i popularna i elitna kultura, omogućio je sovjetskom bloku da u Hladnom ratu može istovremeno napadati sa populističkih pozicija elitnu modernističku kulturu Zapada, pozivajući se na to da je socijalistički realizam kultura stvarana za narod a ne za društvenu elitu, a sa pozicija visoke kulture, pozivajući se na svoju 'ortodoksnu' privrženost evropskim, prosvetiteljskim kulturnim korenima, definisati zapadnu popularnu kulturu kao nekulturu, kulturu lake zabave, narkotičku iluziju efemeralnog karaktera, koja svojim zabavnim karakterom odvraća publiku od 'stvarnih' društvenih problema. Sa sovjetske strane je na taj način borba između pax Sovietica i pax Americana na kulturnom polju okarakterisana kao sukob highbrow i lowbrow kulture. S jedne strane večna, harmonična kultura zasnovana na vekovnim principima klasično-realističke estetike, a sa druge modernistička dekadentna kultura koja iskrivljuje te kanone, proizvodeći moralno devijantna dela. ${ }^{19}$

Institucionalizacija jugoslovenskog socrealističkog filma će slediti u potpunosti sovjetski kulturalni model. Centralizacija filmske delatnosti u Komitetu za kinematografiju i kontrola svih novinarskih pisanja o filmu omogućila je partijskoj strukturi potpunu kontrolu u proizvodnji, distribuciji i konstruisanju značenja filmske kulture. U skladu sa avangardnom

${ }^{17}$ Boris Groys, „Educating the Masses: Socialist Realist Art“, in: Art Power (Cambridge MA: The MIT Press, 2008), 146.

${ }^{18}$ Milovan Đilas, Nova klasa (Beograd: Narodna knjiga, 1990), 39-40.

${ }^{19}$ D. Caute, op. cit., 8. 
doktrinom socijalističkog realizma cilj filmske kulture postaje izgradnja 'novog socijalističkog čoveka', po čuvenoj Staljinovoj formulaciji umetnika kao „inžinjera ljudskih duša“. ${ }^{20}$ Eli Finci piše u časopisu Komiteta za kinematografiju da je cilj filmova da „milionske mase naših trudbenika (...) u njima uče kako treba živeti, šta voleti, čemu se radovati, kojim ljudskim ciljevima težiti." ${ }^{21}$ Cilj filma je da izrazi 'istinu' stvarnosti, koja je istina formulisana od strane Partije iza koje stoje objektivni zakoni Istorije. Ta istina nije dostupna običnom čoveku; novi čovek tek treba da bude stvoren i na Partiji je da stvori takvog 'tipičnog' čoveka, koji odražava esenciju čovečanstva. Predsednik Komiteta za kinematografiju Aleksandar Vučo piše: „Naše društvo u današnjoj, nesumnjivo najsloženijoj etapi svog razvitka, zahteva da se (...) ovaploti (...) u svom tipičnom predstavniku, u 'junaku svoga doba' - u junaku koji kao primer izaziva podražavanje miliona bioskopskih gledalaca, miliona živih ljudi."22 Ovde vidimo upravo ideju socijalističkog realizma u skladu sa Grojsovom interpretacijom potpune fuzije umetnosti sa svakodnevicom, gde društvo ima zadatak 'ovaploćenja' u filmskom umetničkom delu. Običan čovek treba da se 'ovaploti' u idealnog novog socijalističkog čoveka sa ekrana, „čoveka borca, preobrazitelja i borbenog izgraditelja socijalizma, čoveka koga je vaspitala Partija." ${ }^{23}$ Za takav tip čoveka uzor je sovjetski čovek, potpuno uronjen u estetsko-politički model Partije. „Sovjetskom čoveku je nepoznat egocentrizam i nekakav 'odvojeni lični život'. On takav život, otcepljen od života narodnih masa ne može ni da shvati. Velik i mali, izuzetni ili svakodnevni intimni doživljaji sovjetskog čoveka imaju ujedno i socijalni, dakle politički značaj, jer život sovjetskog čoveka teče u okviru života celog društva i naroda, u okviru života koji osvetljava sudbinu svakog pojedinca." ${ }^{24}$

Ukidajući podelu između visoke i niske kulture socijalistički realizam svoj identitet gradi na opoziciji revolucionarno - reakcionarno, buržoasko proletersko, kapitalističko - socijalističko, što će postati naročito izrazito u doba hladnoratovskog zaoštravanja. Jugoslovenski filmski radnici zauzimaju sovjetske pozicije kritike holivudskog i zapadnoevropskog filma: „Vladajuća kinematografija Amerike i zapadnoevropskih zemalja iskoristila je neograničene i uvek u porastu tehničke mogućnosti filma, da bi pažnju gledalaca odstranila od stvarnog sveta i prenela u sferu mistike, šablona,

${ }^{20}$ B. Groys, "The Birth of Socialist Realism from the Spirit of the Russian AvantGarde", 288.

${ }^{21}$ Eli Finci, „Problemi naše filmske kritike“, Film, br. 1-2 (Beograd, jul 1949), 51.

${ }^{22}$ Aleksandar Vučo, „Lik čoveka današnjice u scenariju“, Film, br. 6-7 (Beograd, jul 1948), 62 .

${ }^{23}$ Isto.

24 Aleksandar Vučo, „Velika ostvarenja sovjetske kinematografije“, Film, br. 8-9 (Beograd, decembar 1948), 8. 
melodrame i laži - u sfere udaljene od problema i zahteva radnog naroda. ${ }^{\text {25 }}$ Holivudski film tako biva s jedne strane kritikovan kao popularna kultura, koja se vodi „politikom zaglupljivanja gledalačkih masa“, a s druge kao dekadentna buržoaska umetnost koja se ne bavi aktuelnim temama i „ne tretira pitanja koja interesuju čoveka današnjice." ${ }^{26}$ Kao suprotnost dekadentnom holivudskom filmu uzima se sovjetska filmska umetnost koja pruža „narodima Sovjetskog Saveza i čitavom čovečanstvu dela koja su izraz herojstva, patriotizma, jasnoće perspektive, vere u budućnost i neiscrpnost stvaralačkog elana sovjetskih ljudi."

\section{Film u samoupravnom socijalizmu}

Rezolucija Informbiroa kojom se osuđuje KPJ objavljena je u martu 1948. Inicijalna reakcija jugoslovenskog rukovodstva je bila još jače prihvatanje socijalističkog realizma kao kulturne platforme kako bi se dokazalo da je Rezolucija 'netačna, nepravilna i nepravedna'. Već u zimu 1949. KPJ napušta vera da se sukob može izgladiti i polako se prelazi iz odbrambenog garda u kontraofanzivu. ${ }^{28}$ Istovremeno SAD menjaju svoju politiku prema sukobu Jugoslavija-SSSR prelazeći sa stava watchfull waiting na stav keeping Tito afloat, što je značilo odobrenje kredita i zajmova Jugoslaviji kao i javnu političku podršku u sukobu. Tako je FNRJ promenila stranu u Hladnom ratu. Pregovori o američkoj vojnoj pomoći počinju krajem 1950. da bi do najvećeg približavanja Zapadu došlo potpisivanjem Ankarskog sporazuma februara 1953. i formiranjem Balkanskog saveza naredne godine, kada FNRJ faktički postaje pridruženi član NATO-a. ${ }^{29}$ U skladu sa promenom spoljnopolitičkog kursa menja se i političko-ekonomsko uređenje zemlje. Usled sukoba sa SSSR-om, administrativni, centralistički način političkog uređenja zemlje nije bio moguć, ali ni povratak na zapadnu višepartijsku demokratiju. Jugoslovenski 'treći put' u vidu radničkog samoupravljanja biva uveden kao osobenost zemlje koja navodno jedina počiva na marksističko-lenjinističkoj ortodoksiji i inaugurisan kao najsavršeniji i najnapredniji društveni sistem. Na taj način Jugoslavija je iskazivala svoju nezavisnost od oba bloka.

${ }^{25}$ Aleksandar Vučo, „Naša mlada filmska proizvodnja“, Film, br. 1 (Beograd, decembar 1946), 4.

${ }^{26}$ Dušan Timotijević, „Prvi međunarodni filmski festival u Kanu“, Film, br. 1 (Beograd, decembar 1946), 14.

${ }_{27}^{27}$ A. Vučo, „Velika ostvarenja sovjetske kinematografije“, 11.

${ }^{28}$ Предраг Ј. Марковић, Беоі̄pag између Исйока u Зайаga 1948-1965 (Београд: Службени лист СРЈ, 1996), 77.

${ }^{29}$ Истио, 85-92. 
Do postepenog napuštanja stajališta socijalističkog realizma dolazi u drugoj polovini 1949. godine. Dva najznačajnija događaja u kulturi bila su govor Edvarda Kardelja u Slovenskoj akademiji znanosti i Treći plenum KPJ održan krajem decembra 1949, kada je kulturnoj politici stavljeno u zadatak da vaspitava „slobodne socijalističke ljude, ljude koji smelo i odvažno misle i rade, koji su široki i raznovrsni u shvatanjima, a ne ljude čiji će umovi biti podšišani na isti način. “30 Do zvaničnog prihvatanja drugačijeg stava prema kulturi došlo je na Šestom kongresu 1952. godine, kada je promenjeno ime partije u Savez komunista Jugoslavije. U rezoluciji je istaknuto da se socijalistička kultura može razvijati samo u uslovima slobode mišljenja i kulturnog stvaranja, ali je naglašeno da slobodu ima samo ono mišljenje „koje ima za polaznu tačku borbu za socijalizam i socijalističku demokratiju, za bratstvo i jedinstvo naroda Jugoslavije, za njihovu nezavisnost i nesmetani unutrašnji razvitak, “ jer „niko nema pravo da troši sredstva koja stvara radni narod, a da to bude protiv njegovih napora, njegovih stremljenja i njegovog napretka. "31 Ovom politikom 'dogmatskog antidogmatizma' partija je nedovoljno jasno postavila granice slobode mišljenja u kulturi kako bi imala odrešene ruke da se u nju umeša kada bi za to osetila potrebu. U kulturi je postojao u osnovi jedan stav koji najbolje izražava Kardeljeva izjava o dopuštanju raznim cvetovima da rastu, ali samo ako ostaju u zabranu socijalizma. ${ }^{32}$ Naravno, na Partiji je ostalo da odredi granice tog zabrana shodno svojim trenutnim političkim potrebama. U ovu svrhu Partija se morala obratiti umetnicima i inteligenciji, prepuštajući joj određenu inicijativu u kulturi, ali uvek budno motreći i bivajući konačan arbitar.

Jugoslovenski samoupravni projekat je zasnovan na ideji federalnokomunalnog udruživanja koje bi trebalo da započne proces postepenog izumiranja partije i države. Projekat je ostao na pola puta budući da je $u$ celini stavljen pod okrilje države, što će na polju kulture izazvati stalnu tenziju između navodno autonomnih umetničkih kolektiva i partijskih struktura. Načelno Partija ne propisuje umetnicima šta da stvaraju, ali u praksi reaguje negativno na ono što smatra iskliznućem iz projekta socijalističkog društva. Novu državnu formulu u odnosu prema kulturi najbolje je opisao književni kritičar Sveta Lukić: „Za razliku od sovjetskog dogmatizma, koji umetnicima direktno naređuje da na određeni način nešto učine, kod nas se društvo - preko političara, ideologa i zvaničnih umetnika - dogovara sa

${ }^{30}$ Ljubodrag Dimić, Agitprop kultura: agitpropovska faza kulturne politike u Srbiji: 1945-1952 (Beograd: Rad, 1988), 243-244.

31 „Rezolucija VI kongresa KPJ/SKJ“, u: Borba komunista Jugoslavije za socijalističku demokratiju (Beograd: Rad, 1952), 426-427, citirano u: П. Марковић, н. g., 328.

${ }^{32}$ П. Марковић, н. g., 333. 


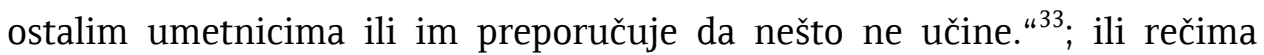
Milovana Đilasa: „Nama političarima politika, vama piscima estetika, a zna se šta je važnije od toga dvoga. ${ }^{\text {" }}{ }^{34}$ Kulturnoj inteligenciji je tako data izvesna autonomija u vođenju kulture, ali je i dalje Partija vukla sve odlučujuće poteze, ne odričući se svoje privilegije da govori u ime socijalističkog naroda.

Filmskim umetnicima i kritičarima, osnivanjem Akademije i profesorima, tako je data izvesna autonomija u obrazovanju filmske kulture, samim tim i društvena moć, kulturni kapital, ali uz neophodno posredovanje Partije. Obrazovanje filmske kulture Jugoslavije biva rastrzano različitim unutarpolitičkim, spoljnopolitičkim i ekonomskim činiocima. Prva stvar koju je trebalo učiniti jeste otklon prema sovjetskom filmu socijalističkog realizma. Aleksandar Vučo, koji je pisao hvalospeve sovjetskoj kinematografiji, sada piše tekst „Velikoruski šovinizam u sovjetskom filmu“. ${ }^{35} \mathrm{U}$ referatu na osnivačkom kongresu Saveza filmskih radnika Jugoslavije, održanom aprila 1950, Vicko Raspor, generalni sekretar Saveza, zaključuje da je od Rezolucije Informbiroa postalo jasno da štetni uticaji na film dolaze ne samo sa Zapada već i sa Istoka. Sovjetski film se optužuje za gušenje drugih nacionalnih kinematografija, reviziju marksizma-lenjinizma, lažno predstavljanje stvarnosti, dogmatizam, dekadenciju, za stavljanje sovjetskih filmova u „Prokrustovu postelju revizionističkih, šovinističkih, hegemonističkih i velikoruskih shvaćanja". ${ }^{36}$

Okretanje ka Zapadu uslovljava uvoz holivudskog filma koji preplavljuje jugoslovenske bioskope nailazeći na oduševljen odziv publike. S jedne strane ovaj izbor je bio uslovljen novom pozicijom u Hladnom ratu, s te strane i ranjivost prema ideologiji pax Americana koja želi da zadobije simpatije evropske publike putem filma („winning hearts and minds“), a sa druge strane ovi filmovi državi donose veliku ekonomsku dobit. ${ }^{37}$ Finansijski razlozi nalažu uvoz popularnih filmova kao i snimanje domaćih filmova popularnog karaktera, provocirajući stalnu hajku od strane partijskog aparata i kulturalne elite protiv zapadnog uticaja, komercijalizacije, kvarenja estetskog ukusa, štetnog uticaja na omladinu itd. Otvaranje prema Zapadu uzrokuje i potrebu da se domaći filmovi prikažu u evropskoj festivalskoj

${ }^{33}$ Sveta Lukić, Savremena jugoslovenska literatura (1945-1965). Rasprava o književnom životu i književnim merilima kod nas (Beograd: Prosveta, 1968), 119.

${ }^{34}$ Isto, 118.

${ }^{35}$ Aleksandar Vučo, „Velikoruski šovinizam u sovjetskom filmu“, Filmska kultura, br. I (1950), 15-20.

${ }^{36}$ Vicko Raspor, „Problemi naše filmske umjetnosti i zadaci saveza filmskih radnika Jugoslavije“, Filmska kultura, br. I (Beograd, 1950), 1-14.

${ }^{37}$ Tehnička pomoć SAD za nabavku filmova Jugoslaviji stiže zajedno sa Tripartitnom pomoći 1952. Od početnih 440.000 dolara, pomoć je do 1955-56. dostigla 615.000 dolara. П. Марковић, н. g., 445. 
mreži. ${ }^{38} \mathrm{Na}$ ovaj način će se jugoslovenski film uključiti u kretanja evropskog umetničkog filma, što će jugoslovenskoj filmskoj eliti dati kulturni kapital stečen u opoziciji prema domaćem i holivudskom popularnom fil$\mathrm{mu},{ }^{39}$ a s druge strane poslužiće vlastima kao dokaz liberalnosti režima $\mathrm{u}$ očima zapadne inteligencije. Iako je umetnički film smatran zvaničnim državnim, nacionalnim visoko-kulturnim produktom, on će često biti na udaru kritike pre svega usled pitanja stranih uticaja, dekadencije i formalizma. On se formira po uzoru na evropski umetnički film i menja se kako se menjaju paradigme umetničkog u evropskom filmu; međutim, jugoslovenski filmski reditelji i kritičari će morati da dokazuju vlastima i javnosti da je jugoslovenski umetnički film rezultat zasebnih domaćih tradicija. Partija je tvrdila da je samoupravni sistem plod autohtonog razvoja jugoslovenskih naroda i film je morao da nađe svoj izvor u vlastitoj domaćoj tradiciji. Iako Partija sada, za razliku od socijalističkog realizma, ne propisuje jednu for$\mathrm{mu}$, film je morao biti socijalistički i nacionalni. Na pitanje šta je to tačno socijalističko i nacionalno nije bilo konačnog odgovora. Nemajući definitivan odgovor Partija je uvek, shodno tekućim potrebama, mogla svako umetničko delo iskritikovati za 'krivo interpretiranje jugoslovenske socijalističke stvarnosti'. Koncept samoupravnog socijalizma je zabranjivao državi da naređuje umetnicima šta da rade, ali je zadržao njeno pravo da vrši kritiku.

Model visoke umetnosti postinformbirovske socijalističke Jugoslavije Sveta Lukić naziva socijalistički estetizam. Ova umetnost, za razliku od socrealizma, nije bila direktno partijska, ali je nastajala kao vrsta dogovora partijske i umetničke elite i stoga je bila podržana od strane upravljačkih struktura i postala zvaničan kulturni model. Ona je, s jedne strane, godila društvenom i materijalnom statusu umetnika, dajući im kulturni kapital zasnovan na navodnoj autonomiji umetničkog polja, a s druge pružala je upravljačkoj eliti političku samopromociju na Zapadu, uključujući se u američku hladnoratovsku 'politiku apolitične umetnosti'. ${ }^{40}$ Larpurlartizam tako postaje glavna odlika ove umetnosti, to jest, 'estetska dispozicija' koju Burdije navodi kao glavnu karakteristiku buržoaske umetnosti, ${ }^{41}$ tako da će ovaj njen elitistički karakter povremeno dolaziti u koliziju sa partijskim strukturama, iako su je one podržavale.

${ }^{38}$ Marijke De Valck, Film Festivals. From European Geopolitics to Global Cinephilia (Amsterdam: Amsterdam University Press, 2007).

${ }^{39}$ Steve Neal, „Art Cinema as Institution“, in: The European Cinema Reader, ed. Catherine Fowler (London/New York: Routledge, 2002), 103-120.

40 Za 'politiku apolitične umetnosti' na primeru slikarstva videti: Nancy Jachec, „Transatlantic Cultural Politics in the late 1950s: the Leaders and Specialists Grant Program", Art History, vol. 26, no. 4, (September 2003), 533-555.

${ }^{41}$ P. Bourdieu, Distinctions, 28-30. 
U formulisanju ideje umetničkog filma jugoslovenski filmski kritičari i teoretičari polaze od razlike prema popularnom filmu. Prema izjavi filmskog kritičara Vicka Raspora cela koncepcija kritike u ranim pedesetim imala je za cilj utemeljenje filma kao umetnosti i njegovo odvajanje od 'šunda', ali tada se nije imao sistematski metod kako to učiniti. ${ }^{42}$ Pristupa se karakterističnoj highbrow varijanti, prema kojoj su umetnička dela komplikovanija od popularnih i prema tome zahtevaju veću intelektualnu aktivnost. „Laki zabavni filmovi biće ispričani mnogo prostijim filmskim jezikom, nego umetnički filmovi koji ulaze u probleme društvenog zbivanja i probleme psihologije i za čije je umetničko rešenje neophodno da se pronađu i primene komplikovanije filmske forme, složenija filmska sredstva izražavanja. (...) Filmski kič, odnosno ono što se u običnom govoru kod nas pogrešno naziva zabavnim filmom, može da bude jasniji ili bliži širem krugu gledalaca, ali ne bez svoje umetničke vrednosti, nego baš zbog uprošćenosti filmskog jezika kojim je ispričan - uprošćenost s obzirom na stepen razvijenosti kulture gledanja filma. ${ }^{433}$

Formula umetničkog filma je ubrzo pronađena u ekranizacijama književnih dela iz kanonizovane nacionalne tradicije. Forsiranje filmova pravljenih po literarnom predlošku klasičnih dela nacionalne književnosti, čija je radnja smeštena u prošlost obojenu folklornim motivima, ima za cilj, osim uključivanja u klimu socijalističkog estetizma koja je obeležena bekstvom od kritičkog prikazivanja sadašnjice, ${ }^{44}$ davanje kulturnog kapitala filmu pozivanjem na kanonizovanu nacionalnu književnu baštinu. Takvom metodom je film, kao potcenjena kulturna kategorija od strane intelektualne elite, trebalo da dobije status umetnosti.

Čini se da je Jugoslavija preuzela od Francuske ovu ideju forsiranja filmskih adaptacija tradicionalnih književnih dela tzv. 'La Tradition de la qualité'. Radi se o filmskim adaptacijama francuskih klasika, kojima francuska kinematografija štiti nacionalni identitet ugrožen invazijom holivudskog filma. ${ }^{45}$ Odavde i insistiranje na ovom žanru kao visoko-kulturnom modelu u Jugoslaviji tokom pedesetih godina. Kulturni kapital koji poseduju dela klasika nacionalne književnosti prenosi se na ovaj način na filmsko polje čineći ova dela reprezentom elitne nacionalne kulture. Ideja evropskog umetničkog filma zasnovana je na mreži filmskih festivala koji filmovima učesnicima festivala, kroz sistem selekcije i nagrađivanja, daju kul-

\footnotetext{
${ }^{42}$ Vicko Raspor, Riječ o filmu (Beograd: Institut za film, 1988), 287.

43 „Kultura gledanja filmova“, Film, br. 5 (Beograd, septembar 1950), 1.

44 Prema Sveti Lukiću formula socijalističkog estetizma u književnosti jeste: „'Što dalje u prošlost - utoliko bolje', 'Što dalje od sadašnjosti - utoliko bliže njoj'. "S. Lukić, n. d., 47.

${ }^{45}$ Susan Hayward, French National Cinema (London/New York: Routledge, 1993), $118-206$.
} 
turni kapital i na taj način ih klasifikuju kao art cinema, tako praveći paralelno filmsko tržište kroz mrežu specijalizovanih bioskopa za ovu vrstu filmova. Na osnovu selekcionisanih jugoslovenskih filmova koji se šalju na inostrane festivale možemo zaključiti da se insistira upravo na filmskim adaptacijama književnih predložaka kao modelu umetničkog filma u ovom dobu. Tako će prva dva jugoslovenska filma u zvaničnoj selekciji Kanskog festivala biti Nevjera Vladimira Pogačića iz 1953, ekranizacije drame Ive Vojinovića Ekvinocio iz 1895, i Hanka Slavka Vorkapića iz 1956, film rađen prema drami Isaka Samokovlije. Nevjera će dobiti i nagradu za najbolji film i najbolju režiju 1955. u okviru obeležavanja deset godina jugoslovenske kinematografije. Adaptacije književnih dela dobijaju i nagrade na novoosnovanom Jugoslovenskom filmskom festivalu u Puli. Filmovi ovog trenda imaju formu tragedije (odatle status 'ozbiljne' umetnosti koju odlikuje 'težina' u odnosu na 'lake' popularne filmove koji se etiketiraju kao zabava), i insistiranje na komplikovanim psihološkim stanjima likova (bavljenje 'unutrašnjošću', psihologijom, to jest domenom duha, u odnosu na bavljenje 'spoljašnjošću', fizičkom akcijom, to jest domenom tela). Filmski kritičar Vicko Raspor insistira na filmsko-literarnom kvalitetu, 'literarnosti', i naziva popularne domaće filmove delima 'vanjske akcije', 'film-stripovima', 'serijskim filmovima' koji su „lišeni brige da nešto stvarno umjetnički dožive i izraze, bezbrižni u odnosu na psihologiju, podtekst, poeziju i filmski izraz“, „u kojima se sva psihologija sastoji samo od najnaturalističkijih fiziološko-bioloških reakcija“ i gde se „proces dramaturškog uobličavanja (...) svodi (...) na šablonsko, prazno konstruiranje fabule bez ikakve literarne vrijednosti." 46

U drugoj polovini pedesetih adaptacije gube primat kao paradigma umetničkog filma. Novi zakon o filmu iz 1956. koji forsira finansiranje filmova na osnovu uspeha na bioskopskim blagajnama čini ovu vrstu filmova, koji nisu bili omiljeni kod publike, ekonomski neisplativom, a s druge strane sve veće insistiranje na bavljenju 'savremenim temama', potisnutim iz jugoslovenske kinematografije, i društvenoj angažovanosti filma učiniće da ovaj žanr izgubi status dominantne paradigme umetničkog. Kao nova paradigma umetničkog filma krajem pedesetih godina javiće se struja filmova sa neorealističkim tendencijama. Neorealizam se $u$ filmu pojavio neposredno posle Drugog svetskog rata u Italiji i obeležen je filmovima koji nastaju pod snažnim uticajem Komunističke partije Italije i prikazuju život nižih klasa i teške socijalne uslove u posleratnoj Italiji. Vremenom, sa slabljenjem uticaja levice $u$ italijanskoj kinematografiji, neorealizam će preći u intimističniju varijantu obeleženu s jedne strane rimokatolicizmom, a s druge egzistenci-

${ }^{46}$ Vicko Raspor: „Metri koji ostaju (1955)“, „Pretenzije (1956)“, „Šest filmova u ovoj sezoni (1955)“, u: V. Raspor, Riječ o filmu, 41-43, 47-48, 99-105. 
jalističkom filozofijom (tzv. 'neorealizam duše') amortizujući socijalne sukobe i transformišući socijalno angažovani neorealistički film u koncept autorskog filma. ${ }^{47}$ Od strane evropske filmske kritike neorealizam će biti inaugurisan kao fundament ideje evropskog art filma i označen istovremeno kao opozit i konceptu komercijalnog holivudskog i sovjetskog propagandnog filma.

Dokaz svesnog insistiranja na neorealizmu jeste angažovanje čuvenog neorealističkog reditelja Đuzepea de Santisa (Giuseppe De Santis) i cele italijanske filmske ekipe od strane Jadran-filma za snimanje filma Cesta duga godinu dana iz 1958. godine. Inostrani uspeh ovog filma (Zlatni globus i nominacija za Oskara u konkurenciji filmova sa neengleskog govornog područja) utro je put italijanskom đaku, reditelju Veljku Bulajiću, koji je završio školu filmske režije u Centro Sperimentale u Rimu. Bulajić će sa dva svoja prva filma, Vlak bez voznog reda (1959) i Uzavreli grad (1961), postati najizrazitiji predstavnik ove struje $u$ jugoslovenskom filmu. Druga struja neorealističkih jugoslovenskih filmova prići će na 'realističniji' način prikazivanju filmova sa temom iz NOB-a (Kroz granje nebo Stoleta Jankovića iz 1958. i Sam Vladimira Pogačića iz 1959). Neorealistički filmovi će na ovaj način postati miljenici kritike, osvajati nagrade na nacionalnom festivalu $u$ Puli i biti selekcionisani za eminentne evropske festivale. S druge strane Partija je dobila filmove koje se bave 'našim socijalističkim temama' kao što je obnova i izgradnja zemlje i NOB, uz umerenu društvenu kritiku koja je davala iluziju permanentne evolucije sistema tako služeći ideologiji neiskrenih 'antibirokratskih reformi'.

Početkom šezdesetih Jugoslavija ulazi u talas 'decentralizirajućih' reformi čiji je imidž na kulturalnom planu trebalo da odrazi mlada grupa filmskih reditelja, kritičara i teoretičara obrazovanih pod uticajem francuskog časopisa Cahiers du cinema. Francuski filmski kritičari i budući reditelji okupljeni oko ovog časopisa afirmisali su ideju autorskog filma, politique des auteurs, ideju koja je temelj u formiranju modernističkog evropskog filma. Njihova filmska teorija je izgrađena u opoziciji prema mainstream-u francuskog filma kao 'lošem drugom', i nasuprot njemu koga smatra industrijom, afirmiše ideju da je film umetnost, da je njegov autor reditelj, a da je specifičnost filmskog medijuma u mise-en-scene-u, formalnoj postavci elementa filmskog jezika, u kome su vidljivi autorov lični pečat i originalnost. Filmovi pripadnika ove grupe i drugih mladih reditelja, koji nisu imali formalno obrazovanje u oficijelnoj filmskoj školi, krajem pedesetih će dolaskom Šarla de Gola (Charles de Gaulle) na vlast biti finansirani iz posebnog fonda i

${ }^{47}$ O italijanskom neorealizmu videti: Simona Monticelli, „Italian post-war cinema and Neo-Realism", in: The Oxford Guide to Film Studies, ed. John Hill, Pamela Church Gibson (Oxford/New York: Oxford University Press, 1998), 455-460. 
snažno podržani od strane novog ministra kulture Andrea Malroa (André Malraux) i progolovske štampe pod sloganom regeneracije i rejuvenalizacije francuske države. ${ }^{48}$

Francuski primer će biti ponovo presađen u Jugoslaviji i novi pokret će biti nazvan jugoslovenski novi film. Veliki uspeh filmskih komedija kod bioskopske publike, koje je omogućio zakon iz 1956. godine, izazvaće talas kritika protiv komercijalizacije filma, a ceh će platiti reditelj Marijan Vajda isključenjem iz Udruženja filmskih umetnika Srbije zbog lošeg umetničkog kvaliteta njegovog filma Šeki snima, pazi se!. Zakon o filmu izmenjen je 1962. u skladu sa decentralizujućim reformama, a kao glavni razlog promene napominje se komercijalizacija filma i potreba „stvaranja filmova veće i trajnije umetničke vrednosti. “49 Zagovornici jugoslovenskog novog filma će sebe afirmisati u opoziciji prema popularnom filmu. Aleksandar Petrović piše: „Poslednjih godina vrši se izvanredno i značajno i presudno preslojavanje. Sa kinematografijom se događa i dogodiće se u relativno kratkom razdoblju, ono što se već odavno zbilo u muzici, plastičnim umetnostima i literaturi; na jednoj strani, to jest po strani, ostaju filmovi zbog kojih takozvana široka publika subotom od 7 do 9 i od 9 do 11 odlazi u bioskop, a na drugoj se otvaraju i osvajaju putevi filmske umetnosti. ${ }^{\text {"50 }}$ Dušan Stojanović piše protiv popularnog filma, za apolitički, umetnički film. „Do juče je film imao zadatak da 'vaspitava' mase, danas mu je 'zadatak' da im pruža zabavu. (...) Masa je politički činilac, a politika i umetnost su različite stvari: dok se političke institucije stvaraju radi naroda i za narod (što znači i prema narodu), u umetnosti potrošač iz mase mora da se uzdigne do individualnog ostvarenja koje je blisko jednom idealu. Umetnost je u tom smislu 'aristokratski' fenomen. ${ }^{\text {"51 }} \mathrm{S}$ druge strane mladi reditelji-kritičari se afirmišu i distanciranjem od aktuelne neorealističke linije. Tako Živojin Pavlović kritikuje vodećeg jugoslovenskog reditelja Veljka Bulajića. Pavlović iz problema filma proteruje sve socijalne konotacije, odbacuje realističku paradigmu i problematiku filma svodi na pitanja formalne estetike. Kvalitet filma se traži u specifično filmskom izrazu, koji je formalne prirode i tiče se stilskog uređenja mise-en-scene-a, što sve upućuje na uticaj francuske politique des auteurs. ${ }^{52}$

${ }^{48}$ Jill Forbes, „The French Nouvelle Vague“, in: The Oxford Guide to Film Studies, 461465.

${ }^{49}$ Nove mere i kretanja u oblasti filma (Beograd: Savremena škola, 1963), 18.

50 Aleksandar Petrović, Novi film, 1950-1965, knjiga I (Beograd: Institut za film, 1971), 91 .

${ }^{51}$ D. Stojanović, $n$. d., 74-75.

52 Живојин Павловић, „Опсене“, u: Беоіраgски филмски критиичарски круі̄, II том (1961-2001), уредник Ранко Мунитић (Ниш: Нишки културни центар, 2005), 509-514. 
Borba za moć na filmskom polju biva tokom šezdesetih zakomplikovana obračunima dve struje unutar Partije, jedne starije, unitarističke, i mlađe, reformatorske, koja se zalagala za veću decentralizaciju republika. ${ }^{53}$ Odatle je borba za prevlast u filmskom polju takođe zadobila oblik generacijskog sukoba implicirajući političke sukobe. Mlađa grupa filmadžija se pozicionirala uz reformatorske političke snage i afirmisala sebe kritikom starije garde reditelja. Tito u početku staje na stranu unitarne linije i lansira napad na stanje u kulturi 1963. godine, usmeravajući ga na „malobrojne, jalove intelektualce, koji naročito u literaturi, slikarstvu i filmu i drugom lebde negdje van naše socijalističke stvarnosti i koji su, uglavnom, nosioci negativnih uticaja iz inostranstva. ${ }^{\text {54 }}$ Filmovi reditelja novog filma će biti zabranjeni i biće sazvana Ideološka komisija koja će sasuti niz optužbi iz socrealističkog arsenala na njih. Veljko Vlahović, predsednik komisije, kritikuje ove filmove zbog ideološkog i estetskog zastranjivanja, nekritičkog imitiranja uticaja sa Zapada, lažnog prikaza socijalističke stvarnosti, formalizma, ističući da ne postoje specifične estetske vrednosti odvojene od društvenih vrednosti. ${ }^{55}$ Tito, međutim, ubrzo menja stranu u sukobu, zabrana se skida sa ovih filmova i već sledeće godine na VIII kongresu SKJ ističe da se Partija neće mešati u poslove kulture. ${ }^{56}$ Konačnu pobedu reformističkog krila Partije predstavljaće pad Aleksandra Rankovića 1966. godine.

Teoretičari i reditelji jugoslovenskog filma staće uz reformatorsko krilo Partije. Svoju teoriju 'novog filma' će sada morati uklopiti u novonastalu političku situaciju i opovrgnuti ranije optužbe o stranim uticajima i umetnosti koja ne odgovara socijalističkoj stvarnosti. 'Novi film' će se rekonceptualizovati kao sinonim procesa sveukupne liberalizacije i debirokratizacije države. Pobeda 'novog filma' biće implicitno tumačena kao pobeda decentralizirajuće frakcije na VIII kongresu. Dušan Stojanović iznosi tezu o 'drugom rađanju jugoslovenske kinematografije' sa 'novim filmom', koji karakteriše kao „antidogmatski i antibirokratski, povezan sa vitalnim interesima društva“, napominjući „da je birokratija odstranjena iz institucija, ali da je i dalje prisutna kao svest u ljudima." ${ }^{57}$ Slobodan Novaković objašnjava da novi film omogućuje gledaocu slobodu da učestvuje u

${ }^{53}$ Ljubodrag Dimić, „Anahrone političke koncepcije i modernizacija. Srbija šezdesetih godina XX veka. Otvaranje pitanja“, u: Dijalog povjesničara - istoričara. knj. 5 . Herceg Novi, 2.-4. ožujka 2001, urednici Hans-Georg Fleck, Igor Graovac (Zagreb: Zaklada Friedrich Naumann, 2002), 409-425.

${ }^{54}$ Prema: П. Марковић, н. g., 337.

55 Милица Комад, „О филмском укусу партијских идеолога - једна епизода из културног живота Југославије“, Гоgишњак за gрушӣвену исииорију, год. VI, св. 1 (Београд, 1999), 57-66.

${ }^{56}$ П. Марковић, н. g., 343-344.

${ }^{57}$ D. Stojanović, n. d., 80-83. 
tumačenju smisla filma, za razliku od klasičnog filma, koji nameće gledaocu fiksirano tumačenje. Moderni film, koji je po Novakoviću izraz senzibiliteta mladih filmskih autora, na ovaj način je prikazan kao antidogmatski, a klasičan, svojina starijih jugoslovenskih reditelja, indirektno optužen kao odraz dogmatizma i birokratije. Iz ovoga prema Novakoviću sledi da su mladi reditelji autori, to jest umetnici, a stariji skromne zanatlije i pripovedači. Takav filmski izraz je odraz društvenih kretanja: „Ovakvi rediteljski postupci su, između ostalog, i posledica dugogodišnjih političkih sloboda i društvenih kretanja u Jugoslaviji, koja su indirektno uslovila određene estetičke inovacije i slobode, što se materijalizovalo u oblasti filmskog izraza. Zato možemo reći da je jugoslovenski moderni film naša vlastita tekovina, a ne produkt nekog nekritičnog odnosa prema 'inostranim uticajima', kao što se povremeno i neistorijski tvrdi. ${ }^{\text {" }} 8$ Filmski festival u Puli će 1965. institucionalizovati pobedu 'novog filma', budući da su na njemu sve značajne nagrade dobili filmovi ovog pravca. Filmovi ovih autora biće podržani od strane liberalnog srpskog republičkog rukovodstva i republičkog ministra kulture Milana Vukosa. Autori i filmski kritičari koji su podržavali jugoslovenski novi film dobijaju istaknute položaje u najvažnijim filmskim i kulturnim institucijama. Reditelj Aleksandar Petrović postaje profesor filmske režije na Akademiji za film, pozorište i radio, predsednik Udruženja filmskih radnika Jugoslavije i član Komisije za kulturne veze sa inostranstvom. ${ }^{59}$ Međutim, nova promena partijskog kursa i Titov obračun sa srpskim liberalnim političkim rukovodstvom 1972. godine. označiće kraj jugoslovenskog novog filma.

Preko Burdijeove teze da različiti umetnički ukusi odslikavaju klasni antagonizam u kapitalističkom društvu pokušali smo da pokažemo kako estetske distinkcije funkcionišu na primeru filmske kulture socijalističke Jugoslavije. Komunistički projekat besklasnog društva pokazao se neuspešnim da proizvede društvo lišeno odnosa dominacije i subordinacije. Socijalistički realizam je pokušao da zamaskira društveni jaz između većine stanovništva i vladajuće partijske birokratije stvarajući uniformnu kulturu za čitavo stanovništvo i totalizujući celo društveno polje jednom umetničkom formom. Projekat jugoslovenskog samoupravnog socijalizma, uslovljen hla-

58 Slobodan Novaković, „Otvaranja (1965)“, u: Vreme otvaranja - ogledi i zapisi o „novom filmu“ (Novi Sad: Kulturni centar, 1970), 163-169.

${ }^{59}$ Reditelji „jugoslovenskog novog filma" će od druge polovine osamdesetih postati najizrazitiji predstavnici tendencije u pozno-jugoslovenskoj i post-jugoslovenskoj kulturi koju istoričar Predrag J. Marković naziva „sindrom retroaktivnog velikomučeništva“. Naime, slabljenjem i konačnim padom socijalističke Jugoslavije njeni intelektualci su bili skloni da preuveličavaju stepen svog otpora vlastima i stepen državne represije. Na ovaj način se negiralo strukturalno mesto koje su navodni disidentski intelektualci imali u samim socijalističkim institucijama. Videti: П. Марковић, н. g., 464. 
dnoratovskim položajem između Istoka i Zapada, nije razvio zaseban kulturni model. Projekat besklasnog samoupravnog društva je krio rascep između nove upravljačke elite i ostatka stanovništva, rascep koji je bio vidljiv u postojanju dve zasebne kulture: elitne kulture socijalističkog estetizma i popularne kulture ostatka stanovništva. Kako bi pokrila društveni rascep politička vlast se često okretala tzv. antibirokratskim reformama, menjajući dominantne kulturalne paradigme kako bi održala iluziju da je $u$ toku proces permanentne samoupravne revolucije i odumiranja države. Povremene hajke kako na elitni tako i na popularni film, trebalo je da održe iluziju da jugoslovensko društvo i njegova kultura idu autohtonim trećim putem socijalizma sa ljudskim likom. U stvari zemlja je sve više i ekonomski i kulturno bila zavisna od zemalja Zapada, a upravljačka elita nevoljna da prepusti vlast 'radnom narodu'.

\section{IZVORI I LITERATURA}

- Филм (Београд, 1946-1949)

- Филм: орі̄ан Савеза филмских раяника Јуі̄ославије (Београд, 1950-1952)

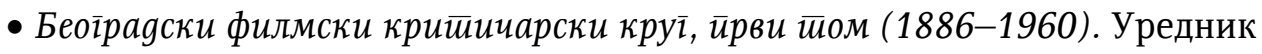
Ранко Мунитић. Ниш: Нишки културни центар, 2002.

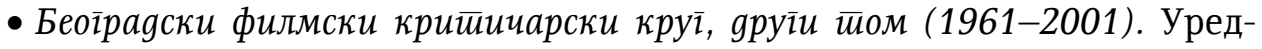
ник Ранко Мунитић. Ниш: Нишки културни центар, 2005.

- Bourdieu, Pierre. Distinctions. A Social Critique of the Judgement of Taste. London: Routledge, 1984.

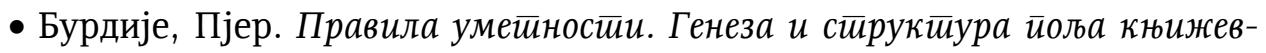
носии. Нови Сад: Светови, 2003.

- Caute, David. The Dancer Defects. The Struggle for Cultural Supremacy during Cold war. Oxford: Oxford University Press, 2003.

- De Valck, Marijke. Film Festivals. From European Geopolitics to Global Cinephilia. Amsterdam: Amsterdam University Press, 2007.

- Dimić, Ljubodrag. Agitprop kultura: agitpropovska faza kulturne politike u Srbiji: 1945-1952. Beograd: Rad, 1988.

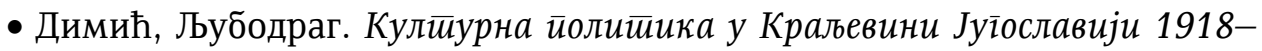

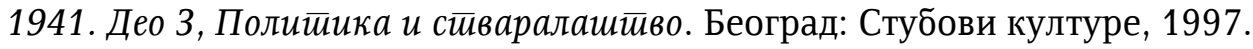

- Dimić, Ljubodrag. „Anahrone političke koncepcije i modernizacija. Srbija šezdesetih godina XX veka. Otvaranje pitanja“. U: Dijalog povjesničara- 
istoričara. knj. 5. Herceg Novi, 2.-4. ožujka 2001. Urednici Hans-Georg Fleck i Igor Graovac, 409-425. Zagreb: Zaklada Friedrich Naumann, 2002.

- Đilas, Milovan. Nova klasa. Beograd: Narodna knjiga, 1990.

- Forbes, Jill. „The French Nouvelle Vague“. In: The Oxford Guide to Film Studies. Editors John Hill and Pamela Church Gibson, 461-465. Oxford/New York: Oxford University Press, 1998.

- Fowler, Bridget. Pierre Bourdieu and Cultural Theory. Critical Investigations. London: Sage, 1997.

- Groys, Boris. „The Struggle against Museum; or, The Display of Art in Totalitarian Space“. In: Museum Culture. Histories, Discourses, Spectacles. Editors Daniel J. Sherman and Irit Rogoff, 144-162. London: Routledge, 1994.

- Groys, Boris. „The Birth of Socialist Realism from the Spirit of the Russian Avant-Garde". In: Post-Impressionism to World War II. Editor Debbie Lewer, 274-295. Oxford: Blackwell, 2006.

- Groys, Boris. „Educating the Masses: Socialist Realist Art“. In: Art Power. 140-147. Cambridge MA: The MIT Press, 2008.

- Harbord, Janet. Film cultures. London: Sage, 2002.

- Hayward, Susan. French National Cinema. London/New York: Routledge, 1993.

- Jachec, Nancy. „Transatlantic Cultural Politics in the late 1950': the Leaders and Specialists Grant Program". Art History, vol. 26, no. 4, (September 2003), 533-555.

- Комад, Милица. „О филмском укусу партијских идеолога - једна епизода из културног живота Југославије“. Гоgищњак за gрушишвену исииориjy, год. VI, св. 1, (Београд, 1999), 57-66.

- Lukić, Sveta. Savremena jugoslovenska literatura (1945-1965). Rasprava o književnom životu i književnim merilima kod nas. Beograd: Prosveta, 1968.

- Марковић, Предраг Ј. Беоїраg између Исйока и Зайаga 1948-1965. Београд: Службени лист СРЈ, 1996.

- Monticelli, Simona. „Italian post-war cinema and Neo-Realism“. In: The Oxford Guide to Film Studies. Editors John Hill and Pamela Church Gibson, 455-460. Oxford/New York: Oxford University Press, 1998.

- Neal, Steve. „Art Cinema as Institution“. In: The European Cinema Reader. Editor Catherine Fowler, 103-120. London/New York: Routledge, 2002.

- Novaković, Slobodan. Vreme otvaranja - ogledi i zapisi o "novom filmu“. Novi Sad: Kulturni centar, 1970.

- Nove mere i kretanja u oblasti filma. Beograd: Savremena škola, 1963.

- Petranović, Branko. Istorija Jugoslavije 1918-1988. Knjiga treća: Socijalistička Jugoslavija 1945-1988. Beograd: Nolit, 1988.

- Petrović, Aleksandar. Novi film, 1950-1965, prva knjiga. Beograd: Institut za film, 1971. 
- Raspor, Vicko. Riječ o filmu. Beograd: Institut za film, 1988.

- Stojanović, Dušan. Velika avantura filma. Beograd/Novi Sad: Prometej, 1998.

- Storey, John. Inventing Popular Culture. From Folklore to Globalization. Oxford: Blackwell, 2003.

- Волк, Петар. Срйски филм. Београд: Институт за филм, 1996.

Rade Pantić

\section{ELITIST AND POPULAR IN THE YUGOSLAV FILM CULTURE 1945-1965}

\section{Summary}

The aim of this article is to try to apply the theory of culture of the French sociologist Pierre Bourdieu, which is based on the distinction between the elitist and the popular, on the domain of the Yugoslav film culture in the period between 1945-1965. Using Bourdieu's hypothesis that conflicting artistic tastes reflect the class antagonism in the capitalist society we tried to show how aesthetic distinctions function in the case of the film culture of socialist Yugoslavia. The communist project of a classless society proved to be incapable of producing a society devoid of relations of domination and subordination. Socialist realism tried to mask the gap between the majority of population and the party bureaucracy by means of abolishing the division between the elite and the popular culture and by creating a uniform culture for the entire population. The entire social field was thus totalised by one art form. The project of Yugoslav selfmanagement socialism, conditioned by the Cold War situation between the East and the West, failed to develop a distinct cultural model. The project of a classless, self-governing society was hiding the gap between the new governing elite and the rest of the population, the gap that was evident in the existence of the two distinct cultures: the elite culture of socialist aestheticism and the popular culture of the rest of the population. In order to cover this social split the rulling communist party would often start the socalled anti-bureaucratic reforms, changing the cultural paradigms in order to maintain the illusion that the process of permanent self-governing revolution and withering away of the state is in progress. Occasional censorship of both elite and the popular film was to maintain the illusion that Yugoslav society and its culture were on the tracks of their own autochto- 
nous third way road of socialism with a human face. In fact the country was more and more economically and culturally dependent of the Western countries, and the governing elite unwilling to cede power to the 'working people'.

KEYWORDS: elite, popular, film, culture, socialism, Bourdieu

\section{L'ÉLITE ET LE POPULAIRE DANS LA CULTURE DU FILM YUGOSLAVE 1945-1965}

\section{Résumé}

Le but de cet article est d'essayer d'appliquer la théorie de la culture du sociologue français Pierre Bourdieu, qui est fondée sur la distinction entre l'élite et le populaire, au domaine de la culture du film yougoslave du periode entre 1945-1965. Utilisant l'hypothèse de Bourdieu que les discordants goûts artistiques reflètent l'antagonisme des classes dans une société capitaliste, nous avons essayer de montrer comment les distinctions esthetiques fonctionnent dans le cas de la culture du film de la Yugoslavie socialiste. Le projet communiste de la société sans classes s'est avéré incapable de produire une société dénuée des relations de domination et subordination. Le réalisme socialiste a essayé de masquer le trou entre la majorité de la population et la bureaucratie de la partie grâce à l'abolition de la division entre l'élite et la culture populaire et créant une culture uniforme pour la population entière. Ainsi, l'entier domaine social a été totalisé par une forme d'art. Le projet du socialisme yougoslave autogestionnaire, conditionné par la situation entre l'Est et l'Ouest pendent la Guerre Froide, n'est pas réussi à développer un modèle culturel distinct. Le projet d'une société autonome sans classe cachait le trou entre la nouvelle élite au pouvoir et le reste de la population, le trou qui était évident dans l'existence de deux cultures distinctes: la culture d'élite du esthétisme socialiste et la culture populaire du reste de la population. Afin de couvrir cette rupture sociale, la partie communiste au pouvoir démarrait souvent les prétendues réformes antibureaucratiques, changeant les paradigmes culturels pour maintenir l'illusion que le processus de la révolution autonome permanente et la diminution de l'état étaient en cours. Les censures occasionnelles de tous les deux, le film d'élite et le film populaire, était pour maintenir l'illusion que la société et la culture yougoslave étaient à la recherche de leur même autochtone route de troisième voie du socialisme à visage 
humain. En fait, le pays était de plus en plus économiquement et culturellement dépendant de pays de l'Ouest et l'élite au pouvoir réticent à ceder ce pouvoir aux 'ouvriers'.

MOTS-CLÉS: élite, populaire, cinéma, culture, socialisme, Bourdie 